\title{
Parametric and Non Parametric Approach in Structural Equation Modeling (SEM): The Application of Bootstrapping
}

\author{
Zainudin Awang ${ }^{1}$, Asyraf Afthanorhan ${ }^{1}$ \& M.A.M. Asri ${ }^{2}$ \\ ${ }^{1}$ Faculty of Economics and Management Sciences, Universiti Sultan Zainal Abidin Kampus Gong Badak, \\ Terengganu \\ ${ }^{2}$ Schools of Informatics and Applied Mathematics, Universiti Malaysia Terengganu, Malaysia \\ Correspondence: Asyraf Afthanorhan, Faculty of Economics and Management Sciences, Universiti Sultan Zainal \\ Abidin Kampus Gong Badak, 21300 Kuala Terengganu, Terengganu. E-mail: ash_18raft@yahoo.com/ \\ zainudinawang@unisza.edu.my/imanasri90@gmail.com
}

Received: February 3, 2015

Accepted: February 13, 2015

Online Published: July 6, 2015

doi:10.5539/mas.v9n9p58

URL: http://dx.doi.org/10.5539/mas.v9n9p58

\begin{abstract}
Lately, there was some attention for the Variance Based SEM (VB-SEM) against that of Covariance Based SEM (CB-SEM) from social science researches regarding the fitness indexes, sample size requirement, and normality assumption. Not many of them aware that VB-SEM is developed based on the non-parametric approach compared to the parametric approach of CB-SEM. In fact the fitness of a model should not be taken lightly since it reflects the behavior of data in relation to the proposed model for the study. Furthermore, the adequacy of sample size and the normality of data are among the main assumptions of parametric test itself. This study intended to clarify the ambiguities among the social science community by employing the data-set which do not meet the fitness requirements and normality assumptions to execute both CB-SEM and VB-SEM. The findings reveal that the result of CB-SEM with bootstrapping is almost similar to that of VB-SEM (bootstrapping as usual). Therefore, the failure to meet the fitness and normality requirements should not be the reason for employing Non-Parametric SEM.
\end{abstract}

Keywords: Variance Based SEM (VB-SEM), Covariance Based SEM (CB-SEM), Fitness Indexes, Normality Assumption, Parametric Statistics, Non Parametric Statistics and Bootstrapping.

\section{Introduction}

Today, the second generation method of multivariate analysis namely Structural Equation Modeling (SEM) is gaining popularity since most researchers and scholars would switch to this particular method in their analysis. SEM is not only popular among academia, but also being employed in variety of sectors. The efficiency of analysis using SEM helps researchers in making proper interpretation of the results and therefore guides them in making right decisions. Several researchers (Bollen, 1989; Byrne et al., 1989; Anderson and Gerbing, 1988; Baron and Kenny, 1988; and Joreskog and Sorbom, 1993) stressed that SEM should be the preferred method for academicians, and even acknowledged that SEM would be great helpful for the next generation researchers.

Subsequently, there are many statistical packages being developed to analyze SEM. Among them are Lisrell, AMOS, M-plus, EQS, and SAS, just to mention a few. However, the Analysis Moment of Structure (AMOS) is the most widely employed among SEM packages since it is being distributed by an IBM, the same distributor of the main statistical software SPSS itself. Even today AMOS is available as one of the choice of analysis methods in IBM-SPSS 20.0 and above. Thus, one does not have to purchase AMOS software separately once he has SPSS 20.0 software.

Esposito (2009) posits that Structural Equation Modeling (SEM) consists of two types known as the Variance Based Structural Equation Modeling (VB-SEM) and the Covariance Based Structural Equation Modeling (CB-SEM). These two packages have great difference in terms of their statistical approaches namely the non-parametric testing and the parametric testing, the objective of the study namely exploratory and confirmatory, and more importantly the algorithm employed namely Generalized Least Square (GLE) and Maximum Likelihood Estimator (MLE).

Unlike the non-parametric procedure in VB-SEM, the parametric procedures in CB-SEM rely on the 
assumptions such as adequate sample size, and normally distributed data. According to Ringle et al. (2010), the non-parametric procedure of SEM can execute the analysis using small sample size, and does not require normal distribution. These two requirements are the main reasons why social science researchers are switching to VB-SEM for their analysis. However, not many of them know that the analysis in VB-SEM is only meant for exploratory study as opposed to confirmatory analysis in CB-SEM (Hair et al., 2014). There are great differences between the types of analysis from the statisticians' point of view.

According to (Hair et al., 2014), the algorithm employed in VB-SEM or popularly known as PLS-SEM (Smart-Pls and Warp-Pls) is Generalized Least Squares (GLS) while the algorithm employed in CB-SEM (Amos, etc.) is the Maximum Likelihood Estimator (MLE). These two types of algorithm differ greatly in term of efficiency of their statistical estimates for path coefficients.

In reality, the VB-SEM (GLS algorithm) completely relies on the bootstrapping procedure or known as resampling with replacement in obtaining the estimates for path coefficients and their respective standard errors. In the meantime, the CB-SEM (MLE algorithm) does not require bootstrapping. However one can execute its bootstrapping procedure in the situation where the normality assumption is not met or for the analysis of non-normal data (Sharma \& Kim, 2013). In this case, (Sharma \& Kim, 2013) also state that MLE bootstrapping (parametric bootstrapping) is appropriate for large data-set compared to PLS. However, if the researcher fails at all to meet the assumption for parametric test in term of sample size requirement, then the VB-SEM should be employed as an alternative and the results is deemed to be exploratory.

In particular, the Variance Based Structural Equation Modeling (VB-SEM) can be divided into two categories namely Partial Least Square Structural Equation Modeling (PLS-SEM) and Generalized Structured Component Analysis (GSCA) but PLS-SEM is more prominent than GSCA. Historically, the analysis procedure in PLS-SEM was first initiated by (Wold \& Martens, 1983) but has been modified by (Chin, 1998) to advance the potential of PLS-SEM in statistical inference. Therefore, PLS-SEM has also gain acceptance as CB-SEM in statistical analysis and has been extensively employed in business and social science researches to model complex relationships.

Nevertheless, most of the statisticians nowadays would not compare the capability of these two SEM approaches (VB-SEM and CB-SEM), instead stressed that the two are complementing each other. In fact, not all methods applied would be perfect in every aspects and situation. They will identify the flaws in CB-SEM and subsequently promote VB-SEM as an alternative. For instance, most of them agree that the requirements of CB-SEM are stringent. Thus four issues being raised namely the fitness measurement of the model, the sample size, the parametric assumptions and the bootstrapping technique. Thus, this paper intend to illuminate the capability of CB-SEM using bootstrap resampling using Amos 21.0 in order to compare with the VB-SEM. Firstly, let's go through briefly the four issues that should be stressed by researchers once to apply SEM.

\subsection{Issue 1: The Required Fitness of a Model}

In CB-SEM, there are two models involved namely measurement model (measuring individual latent construct) and structural model (measuring the inter-relationships among latent constructs). The measurement model should be assessed first prior to modeling structural model (SEM). The assessment of measurement model is made through the Confirmatory Factor Analysis (CFA) procedure for unidimensionality, validity and reliability of items measuring the construct (Zainudin, 2012, 2014). However, the unidimensionality assessment should be made first prior to assessing validity and reliability (Zainudin, 2012, 2014). In unidimensionlity step, the items having low factor loading (less than 0.6) should be deleted while redundant items could either be deleted or constrained (Zainudin, 2012, 2014; Afthanorhan, 2014).

All measurement models need to achieve certain fitness indexes as stated in the literature (Zainudin 2014). The fitness indexes reflect how fit is the measurement model of a construct to the data from the field. Therefore, the assessment of measurement model in the first place is crucial for modeling SEM itself. However, such assessment is only available in CB-SEM rather than in PLS-SEM. In fact the CB-SEM produce many fitness indexes which reflect the appropriateness of a measurement model but it is enough for scholars to report only a few indexes such as Chi-square (Wheaton et al., 1977), Root Mean Square of Error Approximation (Browne \& Cudeck, 1993), Goodness of Fit Index (Joreskog \& Sorbom, 1984), Adjustrd Goodness of Fit Index (Tanaka \& Huba, 1985), Comparative Fit Index (Bentler, 1990), Tucker-Lewis Index (Bentler \& Bonett, 1980), Normed Fit Index (Bollen, 1989), and Chisq/df (Marsh \& Hocevar, 1985). Table 1 present the description of each fit indices: 
Table 1.

\begin{tabular}{ll}
\hline Fit Index & Description \\
\hline Chi square & $\begin{array}{l}\text { To assess the magnitude of discrepancy between the sample and fitted covariance } \\
\text { matrices }\end{array}$ \\
RMSEA & $\begin{array}{l}\text { Sensitive to the number of estimated parameters in the model. It will choose the model } \\
\text { with the lesser number of parameter } \\
\text { Calculate the proportion of variance that is accounted for by the estimated population } \\
\text { covariance }\end{array}$ \\
GFI & $\begin{array}{l}\text { Adjust the GFI based upon degree of freedom. } \\
\text { Tend to increases with sample size }\end{array}$ \\
AGFI & $\begin{array}{l}\text { To assess the model by comparing the } \mathrm{x}^{2} \text { value of the model to the } \mathrm{x}^{2} \text { of the null model } \\
\text { Assumes that all latent variables are uncorrelated (null/independence model) and }\end{array}$ \\
CFI & $\begin{array}{l}\text { compares the sample covariance matrix with this null model } \\
\text { Che estimation process is dependent on the sample data }\end{array}$ \\
Chisq/df &
\end{tabular}

Source: Hooper et al. (2008)

According to Henseler et al. (2009), VB-SEM (PLS-SEM) is aimed at maximizing the explained variance of the endogenous latent construct and does not provide any global goodness-of-fit-criterion. Consequently, Chin (1998) has established a catalog to assess the partial model structures that involve two processes namely the assessment of the outer and inner model. However, these assessment is insufficient to assess the fitness of measurement model since it solely depends on the traditional criterion such as Cronbach Alpha (Nunally, 1978), Composite Reliability (Werts, Lim \& Joreskog, 1974), indicator reliability (Churchill, 1979), Average Variance Extracted (Fornell \& Larcker, 1981), and cross loadings (Chin, 1998; Gotz et al., 2009).

Table 2 .

\begin{tabular}{ll}
\hline Traditional Criterion & Description \\
\hline Cronbach Alpha & $\begin{array}{l}\text { Provide an estimate for the reliability based on the interrelationship } \\
\text { of the measuring items. }\end{array}$ \\
Composite Reliability & $\begin{array}{l}\text { Takes into account that indicators have different loadings } \\
\text { Postulates that a latent variables should explain a substantial part of } \\
\text { Indicator Reliability }\end{array}$ \\
each indicators variance \\
Average Variance Extracted \\
Tross Loadings
\end{tabular}

Source: Henseler et al (2009)

Thereby, one can conclude that the fitness of measurement model in CB-SEM is more acceptable than that of PLS-SEM. This is because the fitness indexes in CB-SEM are more comprehensive to consider of the sample size required, proportion variances and covariance matrix. In addition, CB-SEM also emphasizes of the traditional criterion to ensure all the items and latent construct involved in the study are valid.

However, some researchers prefer doing CFA in PLS-SEM due to the complicated of fitness index provided in CB-SEM and subsequent used PLS-SEM as a solution. In fact, Hair et al. (2011) also states that PLS-SEM is meant for exploratory research while CB-SEM is meant for confirmatory research. Therefore, this paper intends to show that if the researcher failed to achieve the fitness indexes requirement, it is should not be a critical issue since he can still proceed the analysis as long as the study has adequate sample size.

\subsection{Issue 2: The Required Sample Size}

PLS-SEM is deemed as a voodoo modeling that can give benefit to those whom face difficulty to achieve the required sampling (Hair et. al, 2012). This method manages to execute the analysis using small sample size (less than 100) rather than CB-SEM which requires a minimum of 100. In CB-SEM, certain fitness indices are related to sample size such as the parsimonious fit (Chisq/df), and may affect the parameter estimates if the small sample is used. However, the result obtained using CB-SEM is more meaningful if the researcher has more than 
200 data (Hooper et al., 2008).

Although PLS is known for its capability of handling small sample, there is no proof it manages to provide the result similar to CB-SEM in a large data sets. According to Hoyle (1995), the prior research suggests that a sample size of 100 to 200 is usually a good starting point in carrying out path modeling; meaning that path modeling including PLS-SEM needs at least 100 data to conduct the particular analysis, but CB-SEM is much better in handling large sample size. So, the issue of sample size requirement in CB-SEM should not be questioned as long as the researcher manages to obtain at least of 100 data.

\subsection{Issue 3: The Parametric Testing}

For researchers, a requirement to meet the parametric assumption is challenging due to face a variety problem in terms of the total sample size, shape of distribution, and sampling technique used. Sampling technique have two categories namely probability sampling and non-probability sampling (Zainudin, 2010). However, probability sampling more popular compare to nonprobability sampling. In doing statistical inferential, parametric test can be meet if the researcher conduct probability sampling.

CB-SEM also be categorized as parametric test and this assumption causes the problem to researchers. In order to deal with the path modeling, researchers will interest to apply PLS-SEM since the applications employed are much convenient to handle.

In addition, (Ringle et al., 2011) also recommend the data that meet normal assumption should be prioritized CB-SEM since this method was initiated as a parametric test. Otherwise, PLS-SEM was suggested even this method manage to handle a large data sets. (Marcoulides \& Saunders, 2006) states that sample size plays an important role in almost every statistical technique applied in practice. This statement empower our statement that CB-SEM is much better in handling of large data sets rather than PLS-SEM if meet the parametric assumption. Thus, the requirement to handle a parametric assumption should not be raised.

\subsection{Issue 4: The Bootstrapping Technique}

Today, Monte Carlo simulation resampling method dominates the field that can be used to examine parameter estimates and related sample size issues (Marcoulides \& Saunders, 2006). Actually, there are two kind of Monte Carlo strategies namely reactive and proactive Monte Carlo simulation. Thus, some of the PLS package used reactive simulation or otherwise use proactive simulation. In PLS- GRAPH package, the reactive simulation are adopted as jackknife technique (Chin 1998; Denham 1997; Wold 1982). The newest package such as SMART PLS and Warp PLS adopt proactive simulation to obtain the parameter estimates and standard error for hypothesis testing. In order to stabilize the parameter estimates, the number of sample replication was set at 5,000 samples (Ringle et al., 2011).

Therefore, in PLS-SEM one should carry out the bootstrapping procedure alongside the PLS algorithm to obtain the estimates. However, in CB-SEM, the bootstrapping procedure is deemed unnecessary, and it is only conducted to confirm the results obtained by its algorithm.

Furthermore, the Maximum Likelihood Estimator (MLE) that is available in CB-SEM was the best estimator in terms of efficiency as compared to the OLS estimator available in PLS-SEM. According to (Guan, 2003), the MLE and bootstrapping procedure would depend on the sample size in achieving appropriate coverage. Besides, the MLE can be calculated based on non-normal approximation of the distribution of the parameter with performing of bias corrected percentile method as well as bootstrap method (Guan, 2003). In accordance of (Byrne, 2013), the bootstrapping procedure in CB-SEM can handle the non-normal data. Thus, similar to PLS-SEM, CB-SEM also manages to estimate the parameters using the non-normal data as well. (Guan, 2003) goes one step further by claiming that the percentile bias-correction method in CB-SEM gives more appropriate confidence intervals from the bootstrap samples.

\section{Findings}

Figure 1 present the structural model before and after the constraints are employed. At first, the fitness requirement failed to meet the required level, thus some modifications are made based on Modification Indices (MI). The study elects to constraint the correlated items identified through MI in order to increase the fitness indices for the model. At the outset, we perform the CB-SEM using the appropriate procedure to obtain the fitness index and parameter estimation for each construct available. Once we performed the MLE-CBSEM, we intend to include the bootstrap technique in order to make comparison with the PLS-SEM in which synonym its character to apply the bootstrap technique. These steps are discussed to identify whether a gap between the implementation of bootstrap in CB-SEM. Then after, we perform PLS-SEM and subsequent compare with the bootstrap of CB-SEM. 


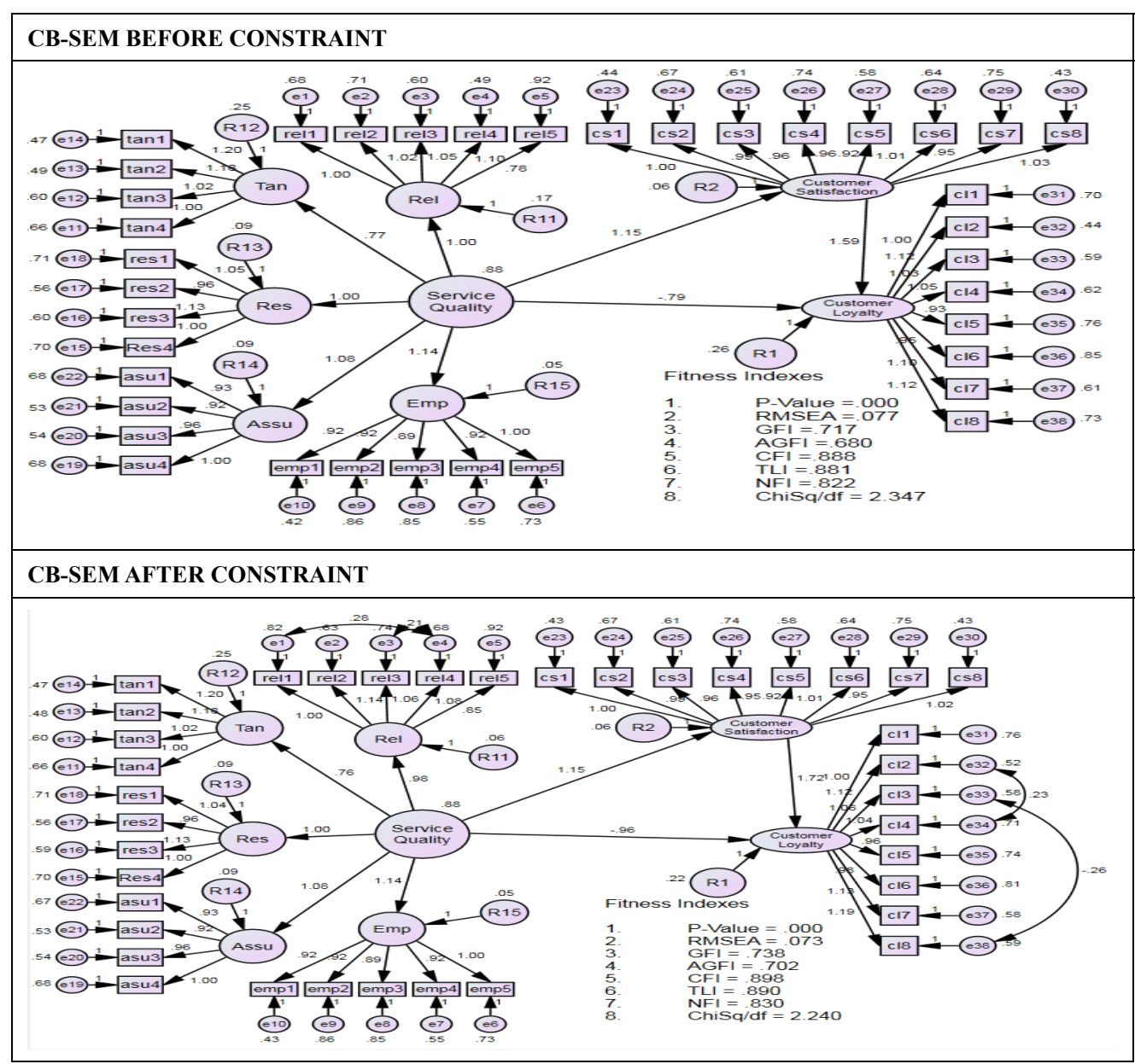

Figure 1. Fitness Indexes Issue (CB-SEM)

Table 3. CBSEM before and after constraint

\begin{tabular}{|c|c|c|c|c|c|c|c|c|c|c|}
\hline \multicolumn{6}{|c|}{ CB-SEM Before Constraint } & \multicolumn{4}{|c|}{ CB-SEM After Constraint } & \multirow[t]{2}{*}{ Result } \\
\hline Endogenous & Exogenous & Estimate & Std Error & C.R & $\mathbf{P}$ & Estimate & Std Error & C.R & $\mathbf{P}$ & \\
\hline Service & Customer & 1.152 & .088 & 13.084 & $* * *$ & 1.153 & .088 & 13.123 & $* * *$ & Supported \\
\hline Quality & Satisfaction & & & & & & & & & \\
\hline $\begin{array}{l}\text { Service } \\
\text { Quality }\end{array}$ & Reliability & .972 & .090 & 10.750 & $* * *$ & .980 & .091 & 10.809 & $* * *$ & Supported \\
\hline $\begin{array}{l}\text { Service } \\
\text { Quality }\end{array}$ & Tangibles & .764 & .079 & 9.655 & $* * *$ & .762 & .079 & 9.652 & $* * *$ & Supported \\
\hline $\begin{array}{l}\text { Service } \\
\text { Quality }\end{array}$ & Responsiveness & 1.000 & & & & 1.000 & & & & Supported \\
\hline $\begin{array}{l}\text { Service } \\
\text { Quality }\end{array}$ & Assurance & 1.081 & .092 & 11.714 & $* * *$ & 1.078 & .092 & 11.709 & $* * *$ & Supported \\
\hline $\begin{array}{l}\text { Service } \\
\text { Quality }\end{array}$ & Empathy & 1.143 & .096 & 11.956 & $* * *$ & 1.141 & .095 & 11.965 & $* * *$ & Supported \\
\hline $\begin{array}{l}\text { Customer } \\
\text { Satisfaction }\end{array}$ & $\begin{array}{l}\text { Customer } \\
\text { Loyalty }\end{array}$ & 1.591 & .404 & 3.939 & $* * *$ & 1.637 & .421 & 3.894 & $* * *$ & Supported \\
\hline $\begin{array}{l}\text { Service } \\
\text { Quality }\end{array}$ & $\begin{array}{l}\text { Customer } \\
\text { Loyalty }\end{array}$ & -.790 & .467 & -1.693 & .090 & -.861 & .486 & -1.772 & .076 & $\begin{array}{c}\text { Not } \\
\text { Supported }\end{array}$ \\
\hline
\end{tabular}

Table 3 present the result of path coefficient using ML estimation in CB-SEM once completely employed constraints in structural model. Basically, the constraints are applied to achieve the fitness requirement besides to remedy the multicollinearity problem. The main aim of this research is to use this unfit structural model as a 
research subject to compare with the PLS-SEM.

Table 4. Maximum Likelihood Estimator and Bootstrap

\begin{tabular}{|c|c|c|c|c|c|c|c|c|c|c|}
\hline \multirow{2}{*}{ Exogenous } & \multicolumn{5}{|c|}{ CB-SEM (Maximum Likelihood Estimator) } & \multicolumn{4}{|c|}{$\begin{array}{c}\text { CB-SEM } \\
\text { (Corrected Bias Percentile Method) }\end{array}$} & \multirow[t]{2}{*}{ Result } \\
\hline & Endogenous & Estimate & $\begin{array}{c}\text { Std } \\
\text { Error }\end{array}$ & C.R & $\mathbf{P}$ & Estimate & $\begin{array}{c}\text { Std } \\
\text { Error }\end{array}$ & C.R & $\mathbf{P}$ & \\
\hline Service & Customer & 1.153 & .088 & 13.123 & $* * *$ & 1.153 & .088 & 13.123 & $0.002 * * *$ & Supported \\
\hline Quality & Satisfaction & & & & & & & & & \\
\hline Service & Reliability & .980 & .091 & 10.809 & $* * *$ & .980 & .091 & 10.809 & $0.001 * * *$ & Supported \\
\hline \multicolumn{11}{|l|}{ Quality } \\
\hline Service & Tangibles & .762 & .079 & 9.652 & $* * *$ & .762 & .079 & 9.652 & $0.002 * * *$ & Supported \\
\hline \multicolumn{11}{|l|}{ Quality } \\
\hline Service & Responsiveness & 1.000 & & & & 1.000 & & & & \\
\hline \multicolumn{11}{|l|}{ Quality } \\
\hline Service & Assurance & 1.078 & .092 & 11.709 & $* * *$ & 1.078 & .092 & 11.709 & $0.002 * * *$ & Supported \\
\hline \multicolumn{11}{|l|}{ Quality } \\
\hline Service & Empathy & 1.141 & .095 & 11.965 & $* * *$ & 1.141 & .095 & 11.965 & $0.002 * * *$ & Supported \\
\hline \multicolumn{11}{|l|}{ Quality } \\
\hline Customer & Customer & 1.637 & .421 & 3.894 & $* * *$ & 1.637 & .421 & 3.894 & $0.001 * * *$ & Supported \\
\hline Satisfaction & Loyalty & & & & & & & & & \\
\hline Service & Customer & -.861 & .486 & -1.772 & .076 & -.861 & .486 & -1.772 & 0.059 & Not \\
\hline Quality & Loyalty & & & & & & & & & Supported \\
\hline
\end{tabular}

Table 4 present the result of CB-SEM between MLE and Corrected bias percentile method. By inspecting through of the probability value, almost all of the exogenous construct are significant impact on endogenous constructs unless service quality on customer loyalty. In doing different approach, both of these approach provide the same result. Therefore, it can be indicate that the executing using MLE is adequate to solve the path modeling in while bootstrap can be handled for the confirmation result. As aforementioned, bootstrap also managed to handle non-normal data in accordance of Byrne (2013). Thus, this structural model will proceed for the subsequent analysis. Plus, based on result of parameter estimate and standard error for ML-CBSEM and Bootstrap CBSEM, both of these results are equivalent. This is because the bootstrap technique do not affect on parameter estimate but on the standard error. Thereby, bootstrap technique is often used for producing the standard error so that can help the researchers to attain the hypothesis testing. In this case, we claim that the implementation of maximum likelihood in CB-SEM is quite enough since the significant test is same. In other words, MLE is absolutely robust and high consistent in obtaining of parameter estimates and hypotheses testing.

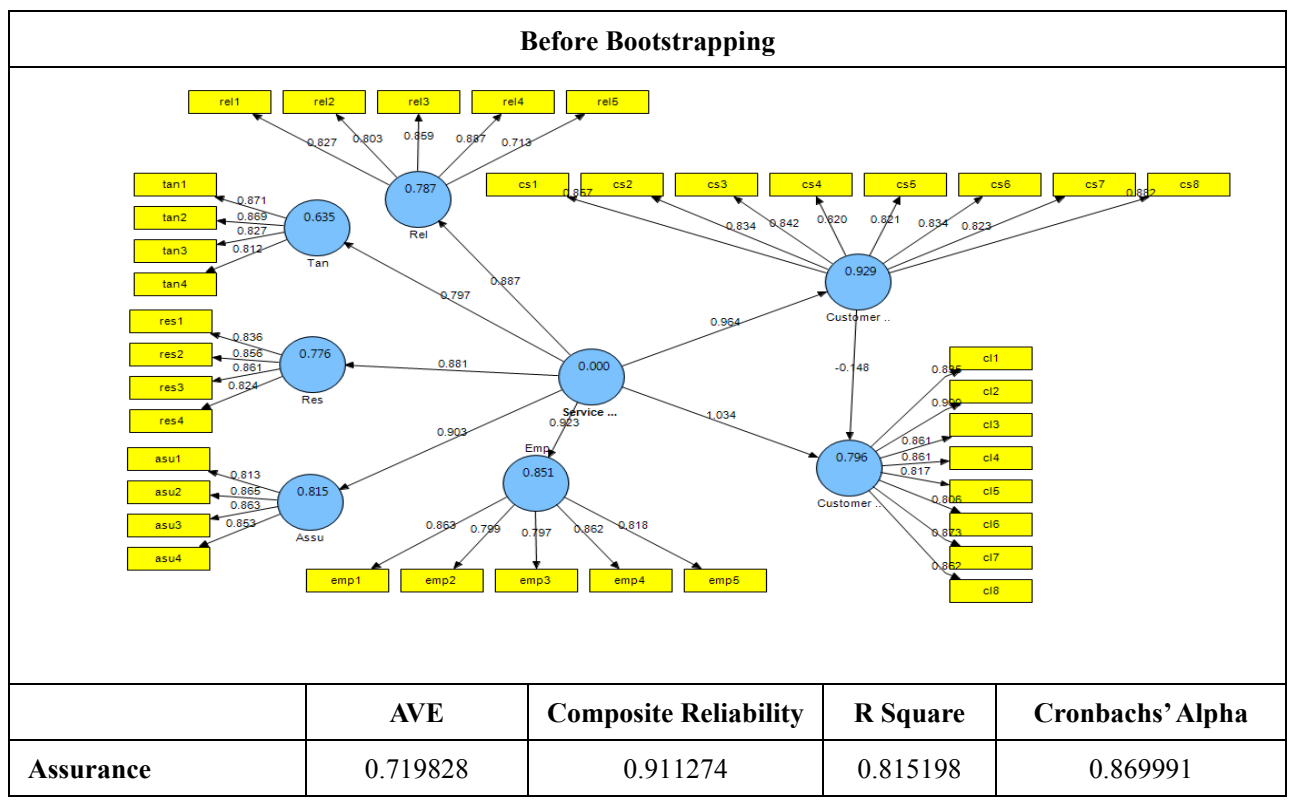




\begin{tabular}{|l|l|l|l|l|}
\hline Customer Loyalty & 0.726425 & 0.954991 & 0.796082 & 0.945985 \\
\hline $\begin{array}{l}\text { Customer } \\
\text { Satisfaction }\end{array}$ & 0.704686 & 0.950196 & 0.928763 & 0.940042 \\
\hline Empathy & 0.686217 & 0.916113 & 0.851280 & 0.885328 \\
\hline Reliability & 0.672463 & 0.910802 & 0.786890 & 0.876637 \\
\hline Responsiveness & 0.713060 & 0.908568 & 0.776054 & 0.865786 \\
\hline Service Quality & 0.572903 & 0.980671 & & 0.979636 \\
\hline Tangibles & 0.713891 & 0.908854 & 0.635229 & 0.866002 \\
\hline
\end{tabular}

Figure 2 and Table 5. Partial Least Square Structural Equation Modeling (PLS-SEM)

Figure 2 present the structural model which is the same data as implement in CB-SEM. Once execute the PLS algorithm, the traditional criterion were suggested as reliable and valid. Therefore, the items and latent constructs involved in the study reliable to proceed. However, the global fitness for each measurement model does not exist

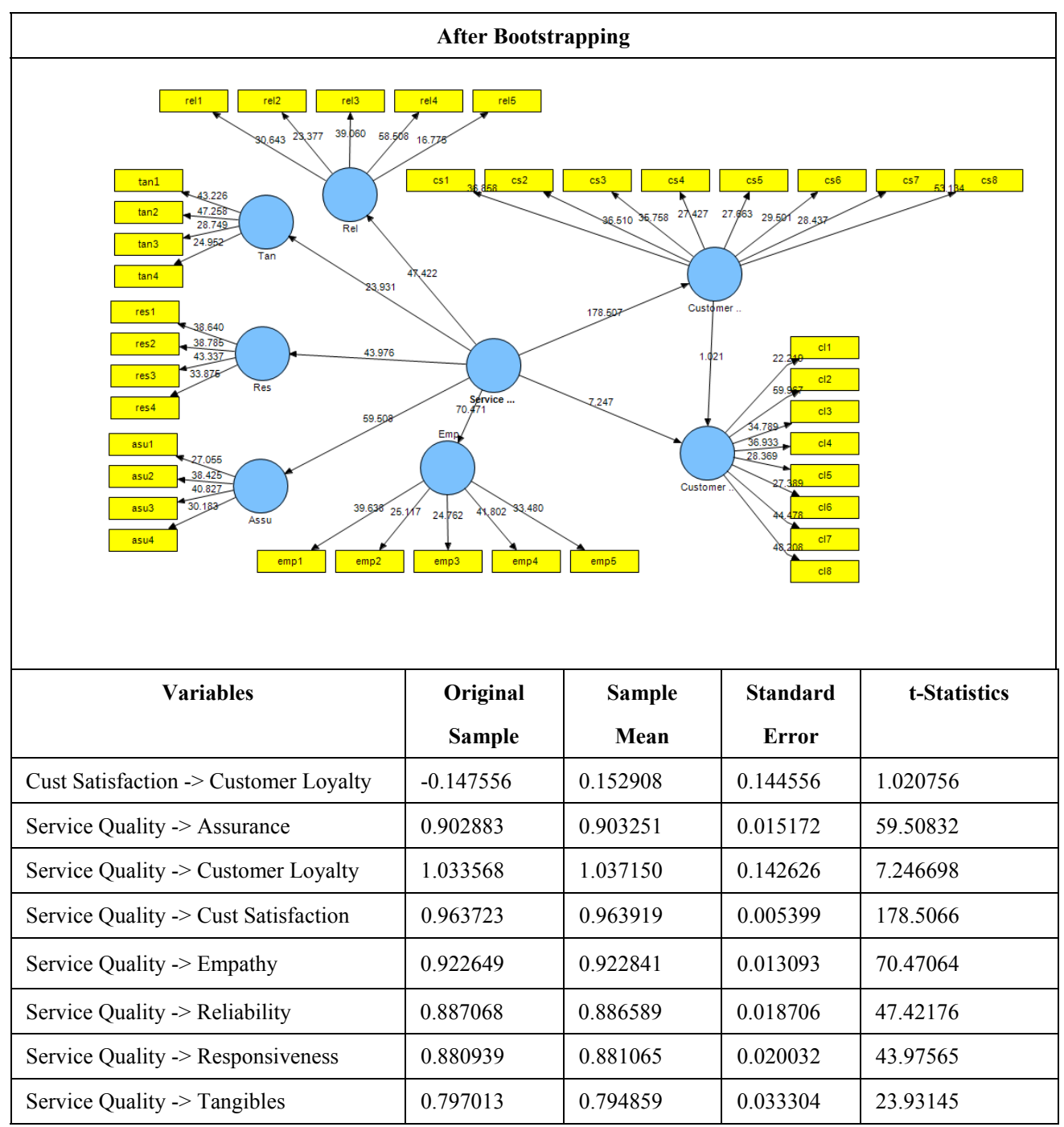

Figure 3 and Table 6. Partial Least Square Structural Equation Modeling (PLS-SEM) 
Table 7. Bootstrap between CB-SEM and PLS-SEM

\begin{tabular}{|c|c|c|c|c|c|c|}
\hline \multirow[b]{2}{*}{ Variable } & \multicolumn{3}{|c|}{ VB-SEM } & \multicolumn{3}{|c|}{ CB-SEM } \\
\hline & Estimate & Standard Error & t-Statistics & Estimate & Standard Error & P-Value \\
\hline Cust Satisfaction -> Cust Loyalty & -0.147556 & 0.144556 & 1.021 & 1.637 & .421 & $0.001 * * *$ \\
\hline Service Quality -> Assurance & 0.902883 & 0.015172 & $59.51 * * *$ & 1.078 & .092 & $0.002 * * *$ \\
\hline Service Quality -> Customer Loyalty & 1.033568 & 0.142626 & $7.247 * * *$ & -.861 & .486 & .059 \\
\hline Service Quality -> Cust Satisfaction & 0.963723 & 0.005399 & $178.51 * * *$ & 1.153 & .088 & $0.002 * * *$ \\
\hline Service Quality -> Empathy & 0.922649 & 0.013093 & $70.471 * * *$ & 1.141 & .095 & $0.002 * * *$ \\
\hline Service Quality -> Reliability & 0.887068 & 0.018706 & $47.422 * * *$ & .980 & .091 & $0.001 * * *$ \\
\hline Service Quality -> Responsiveness & 0.880939 & 0.020032 & $43.976 * * *$ & 1.00 & NA & NA \\
\hline Service Quality -> Tangibles & 0.797013 & 0.033304 & $23.931 * * *$ & .762 & .079 & $0.002 * * *$ \\
\hline
\end{tabular}

Table 7 present comparisons between PLS-SEM and CB-SEM after performing bootstrap technique. By inspecting through PLS-SEM results, almost exogenous construct have significant impact on endogenous constructs unless Customer Satisfaction towards Customer Loyalty which is contrary on the result of CB-SEM. In CB-SEM output, Service Quality on Customer Loyalty is insignificant. Although both of these method applied are different in methodological concept but they almost provide same result. In fact, the data obtained are failed to meet the requirement of fitness index based on the result of CB-SEM. Therefore, it can be proof that the issue of fitness measurement model in CB-SEM is not a critical issue. In addition, the maximum likelihood estimator applied in Table 1 shows the equivalent significant with the bootstrap technique applied in CB-SEM. Means that, MLE is very robust in the relationship of the path analysis and this consistency of estimator do not impair on hypothesis testing.

\section{Conclusion and Recommendation}

At the outset, the authors have discussed four issue that should be addressed namely the fitness of measurement model, the adequacy of sample size, the parametric assumptions and the bootstrapping techniques. These issues have caused worry among the researchers for those interested to apply CB-SEM in their research work. Truthfully, these four issue can be handled even the measurement model is fail to meet the fitness index requirement. Table 5 which the result between PLS-SEM and CB-SEM had justify that almost these entire variable involved in the study provide the same result.

Moreover, the other three issues such as sample size requirement, parametric assumption and bootstrap technique also has been explained in previous subtopics. The minimum sample size required in structural equation modeling is 100 if the researchers intend to have a good starting point to conduct the path modeling. This method is including of PLS-SEM. Means that, the good finding for path modeling should be higher than 100 of data sets and subsequent justify that the findings which has a small sample size can be arguable.

Parametric test definitely need a properly assumption as employed in CB-SEM. However, if the researchers have the data that meet all the requirement of parametric assumptions, the finding will be meaningful rather than PLS-SEM that has been proved by the founder of Smart PLS.

Table 2 present the result between MLE and bias corrected percentile (bootstrap) using CB-SEM. Both of this method suggests the very similar result. Thus, it can be indicated that the researchers still can continuously depend on MLE to carry on their research without the implementation of bootstrap; in addition, MLE has been proved as a best estimator in terms of efficiency. Ultimately, the authors suggest that the researchers still can conduct their research using CB-SEM in a minimum rate of fitness requirement. In addition, the researchers recommended should appropriately conduct PLS-SEM and CB-SEM instead to compare each other. The finding would be more valuable if the research applied is complementing each other.

\section{Competing Interest}

Authors have declared that no competing interests exist.

\section{Acknowledgement}

The authors thank Nazim Aimran for his support of the data collection for this study.

\section{References}

Anderson, J. C., \& Gerbing, D. W. (1988). Structural equation modeling in practice: A review and recommended two-step approach. Psychological bulletin, 103(3), 411. http://dx.doi.org/10.1037/0033-2909.103.3.411 
Awang, Z. H. (2010). Research Methodology for Business and Social Science. UiTM Press. Shah Alam, Malaysia.

Baron, R. M, \& Kenny, D. A. (1986). The Moderator-Mediator variable distinction in social psychological research: Conceptual, strategic, and statistical considerations. Journal of Personality and Social Psychology, 51, 1173-1182. http://dx.doi.org/10.1037/0022-3514.51.6.1173

Bentler, P. M. (1990). Comparative fit indexes in structural models. Psychological bulletin, 107(2), 238. http://dx.doi.org/10.1037/0033-2909.107.2.238

Bentler, P. M., \& Bonett, D. G. (1980). Significance tests and goodness of fit in the analysis of covariance structures. Psychological Bulletin, 88, 588-606. http://dx.doi.org/10.1037/0033-2909.88.3.588

Bollen, K. A. (1989). A new incremental fit index for general structural equation models. Sociological Methods \& Research, 17(3), 303-316. http://dx.doi.org/10.1177/0049124189017003004

Bollen, K. A. (1989). Structural Equations with Latent Variables, Wiley \& Sons, New York, NY. http://dx.doi.org/10.1002/9781118619179

Browne, M. W., \& Cudeck, R. (1993). Alternative ways of assessing model fit. Sage Focus Editions, 154, 136-136.

Byrne, B. M. (2013). Structural equation modeling with AMOS: Basic concepts, applications, and programming. Routledge.

Byrne, B. M., Shavelson, R. J., \& Muthén, B. (1989). Testing for the equivalence of factor covariance and mean structures: The issue of partial measurement invariance. Psychological Bulletin, 105(3), 456. http://dx.doi.org/10.1037/0033-2909.105.3.456

Chin, W. W. (1998). Commentary: Issues and opinion on structural equation modeling.

Churchill, Jr. G. A. (1979). A paradigm for developing better measures of marketing constructs. Journal of marketing research, 64-73. http://dx.doi.org/10.2307/3150876

Denham, M. C. (1997). Prediction intervals in partial least squares. Journal of Chemometrics, 11(1), 39-52. http://dx.doi.org/10.1002/(SICI)1099-128X(199701)11:1<39::AID-CEM433>3.0.CO;2-S

Esposito, V. V. (2009). PLS path modeling and PLS regression: A joint partial least squares component-based approach to structural equation modeling. IFCS@GFKL-Classification as a Tool for Research (IFCS 2009).

Fornell, C., \& Larcker, D. F. (1981). Structural equation models with unobservable variables and measurement error: Algebra and statistics. Journal of marketing research, 382-388. http://dx.doi.org/10.2307/3150980

Go"tz, O., Liehr-Gobbers, K., \& Krafft, M. (2009). Evaluation of structural equation models using the partial least squares (PLS) approach. In: V. Esposito Vinzi, W. W. Chin, J. Henseler, \& H. Wang (Eds), Handbook of partial least squares: Concepts, methods, and applications. Berlin: Springer (in print).

Guan, W. (2003). From the help desk: bootstrapped standard errors In H. J. Newton (Ed.), The Stata Journal (College Station, TX: Stata Press, 2003), 71-80.

Hair, J. F., Ringle, C. M., \& Sarstedt, M. (2011). PLS-SEM: Indeed a silver bullet. The Journal of Marketing Theory and Practice, 19(2), 139-152. http://dx.doi.org/10.2753/MTP1069-6679190202

Hair, J. F., Sarstedt, M., Ringle, C. M., \& Mena, J. A. (2012). An assessment of the use of partial least squares structural equation modeling in marketing research. Journal of the Academy of Marketing Science, 40(3), 414-433. http://dx.doi.org/10.1007/s11747-011-0261-6

Henseler, J., Ringle, C. M., \& Sinkovics, R. R. (2009). The use of partial least squares path modeling in international marketing. Advances in international marketing, 20, 277-319. http://dx.doi.org/10.1108/S1474-7979(2009)0000020014

Hooper, D., Coughlan, J., \& Mullen, M. (2008). Structural equation modelling: guidelines for determining model fit. Articles, 2.

Hoyle, R. H. (Ed.). (1995). Structural equation modeling: Concepts, issues, and applications. Sage Publications.

Joreskog, K. G., \& Sorbom, D. (1984). LISREL VI: Analysis of linear structural relationships by maximum likelihood, instrumental variables, and least square methods [Computer program]. Mooresville, IN: Scientific Software. 
Jöreskog, K. G., \& Sörbom, D. (1993). LISREL 8: Structural equation modeling with the SIMPLIS command language. Scientific Software International.

Marcoulides, G. A., \& Saunders, C. (2006). PLS: A silver bullet?. Management Information Systems Quarterly, $30(2), 1$.

Marsh, H. W., \& Hocevar, D, (1985). Application of confirmatory factor analysis to the study of self concept: First and higher-order factor models and their invaHance across groups. Psychological Bulletin, 97, 562-582. http://dx.doi.org/10.1037/0033-2909.97.3.562

Mohamad, W., Bin, A., \& Afthanorhan, W. (2014). Hierarchical Component Using Reflective-Formative Measurement Model In Partial Least Square Structural Equation Modeling (pls-Sem). International Journal of Mathematics and Statistics Invention (IJMSI), 2(2), 55-71.

Nunally, J. C., \& Bernstein, I. H. (1978). Psychometric theory.

Ringle, C. M., Wende, S., \& Will, A. (2010). Finite mixture partial least squares analysis: Methodology and numerical examples. In Handbook of Partial Least Squares (pp. 195-218). Springer Berlin Heidelberg. http://dx.doi.org/10.1007/978-3-540-32827-8_9

Sharma, P. N., \& Kim, K. H. (2013). A comparison of PLS and ML bootstrapping techniques in SEM: A Monte Carlo study. In New perspectives in partial least squares and related methods (pp. 201-208). Springer New York. http://dx.doi.org/10.1007/978-1-4614-8283-3_13

Tanaka, J. S., \& Huba, G. J. (1985). A fit index for covariance structures model under arbitrary GLS estimation. British Journal of Mathematical and Statistical Psychology, $38 . \quad$ 197-208. http://dx.doi.org/10.1111/j.2044-8317.1985.tb00834.x

Werts, C. E., Linn, R. N., \& Karl, G. J. (1974). InterclassReliability Estimates: Testing Structural Assumptions. Educational \& Psychological Measurement, 34, 25-33. http://dx.doi.org/10.1177/001316447403400104

Wheaton, B., Muthen, B., Alwin, D., F., \& Summers, G. (1977). Assessing Reliability and Stability in Panel Models. Sociological Methodology, 8(1), 84-136. http://dx.doi.org/10.2307/270754

Wold, S., Martens, H., \& Wold, H. (1983). The multivariate calibration problem in chemistry solved by the PLS method. In Matrix pencils (pp. 286-293). Springer Berlin Heidelberg.

Zainudin, A. (2014). A Handbook on SEM. MPWS Publisher. Bangi Malaysia (pp.61-64).

\section{Copyrights}

Copyright for this article is retained by the author(s), with first publication rights granted to the journal.

This is an open-access article distributed under the terms and conditions of the Creative Commons Attribution license (http://creativecommons.org/licenses/by/3.0/). 